\title{
Accelerated Wound Healing on the Skin Using a Film Dressing with $\boldsymbol{\beta}$-Glucan Paramylon
}

\author{
KOSUKE YASUDA $^{1}$, MISA OGUSHI ${ }^{2,3}$, AYAKA NAKASHIMA ${ }^{1}$, YOSHIHISA NAKANO $^{2}$ and KENGO SUZUKI ${ }^{1}$ \\ ${ }^{1}$ euglena Co., Ltd., Tokyo, Japan; \\ ${ }^{2}$ Osaka Prefecture University, Osaka, Japan; \\ ${ }^{3}$ Hagoromo University of International Studies, Osaka, Japan
}

\begin{abstract}
Background/Aim: $\beta$-Glucan has been shown to modulate immune system and potentially aid wound healing. A naturally-available $\beta$-glucan, paramylon, is available in the form of a film, which would be an ideal form to use in wound care. The aim of this study was to examine the therapeutic efficacy of paramylon film as a wound dressing. Materials and Methods: An acute wound was created on the skin of the posterior aspect of mice and wound healing was observed for 5 days. Mice were treated with either paramylon film or conventional cellulose film. Results: The time course of changes in wound size revealed that paramylon film dressing application leads to significantly faster wound contraction than conventional cellulose film. The dressing suppressed elevation of the inflammatory cytokines interferon gamma, interleukin-6, and vascular endothelial growth factor. Conclusion: $\beta$-Glucan paramylon film can facilitate wound healing by inhibiting inflammatory aggression and has potential application as a novel wound dressing.
\end{abstract}

Appropriate and optimal wound care is crucial, especially in the presence of pathology. Increased prevalence of obesity and diabetes further emphasize the benefit and need for improved wound care (1). A recent study revealed that wound healing is facilitated by a moist dressing (2). Moist wound healing is a therapeutic method with exudate as the humectant to protect and provide a moist environment for the wound. Cellulose materials such as a bandage or gauze is used in clinical wound care. Different types of wound dressing materials are available for all wound types (e.g., polyurethane foams, hydrocolloids, iodine-containing gels,

This article is freely accessible online.

Correspondence to: Kengo Suzuki, euglena Co., Ltd., 5-29-11 Shiba, Minato-ku, Tokyo, 108-0014, Japan. Tel: +81 334544907, Fax: +81 354424907, e-mail: suzuki@euglena.jp

Key Words: $\beta$-glucan, paramylon, wound dressing, cytokine. biomaterials) (2). Furthermore, modification by collagen and different antimicrobial agents was carried out to enhance the properties of the wound dressing materials $(3,4)$.

Skin wound healing involves multiple processes: (1) hemostasis, (2) inflammation, (3) proliferation, and (4) remodeling (5). Inflammation is a tissue defense mechanism, and provides resistance to microbial contaminations (6). Inflammation occurs almost simultaneously with hemostasis, and starts from within a few minutes to $24 \mathrm{~h}$ from injury and lasts for about 3 days (7). Proliferation starts at approximately day 3 , in which keratinocytes and fibroblasts start to proliferate and migrate toward the wound (8). Failed regulation of any particular process results in pathologically compromised wound healing, such as chronic wounds, which are characterized by a prolonged or excessive inflammatory phase, persistent infections, and delayed wound contraction (8).

$\beta$-glucan, a polysaccharide comprised of $\beta$-linked D-glucose molecules, are extracted from various sources, such as cereal grains, mushrooms, seaweeds, and yeast (9). The yeast $\beta$ glucans promote wound repair. The immunomodulatory properties of $\beta$-glucan have been known for decades and dietary supplements are commercially available with an aim to improve the health of individuals (10). Meta-analyses of clinical studies demonstrate the beneficial effects of $\beta-1,3 / 1,6-$ glucans lentinan in anticancer therapy $(11,12)$. $\beta$-glucans trigger a group of immune cells including macrophages and neutrophils (13). $\beta$-Glucans inhibit tumor development (14), activate macrophage function (15), and induce production of cytokines (16) and nitric oxide synthase (17), as well as prevent bacterial wound infections by stimulation of the host immune system (18) and induce the macrophage release of wound growth factors (19). Due to its immunomodulatory activities, macrophage-stimulating $\beta$-glucan enhances wound healing in diabetic animals and patients $(20,21)$. $\beta$-Glucan is a natural product and immunomodulator that has been predicted to enhance rapid wound healing.

Paramylon ( $\beta$-1,3-D-glucan) is a naturally-occurring compound isolated from Euglena gracilis $\mathrm{Z}$. The yield of paramylon from Euglena gracilis $\mathrm{Z}$ amounts to 
approximately $60-70 \%$ of the dried cells. Paramylon consists of only glucose (mean, 700 glucose molecules). Currently, paramylon has been shown to possess immune-potentiating activity (22), anti-atopic dermatitis effects (23), hepatoprotective effects with antioxidant effects (24), and antimicrobial activity (25). Paramylon has been developed as a polysaccharide nanofiber and thermoplastic and as a transparent thin film (26-28), which enabled the use of paramylon as a wound care material. Similar to bacterial cellulose, paramylon film can maintain a moist environment at the wound surface. However, its full utility has yet to be demonstrated. To our best knowledge, no literature is currently available on $\beta$-glucan paramylon film applied directly to the skin as a moist wound dressing.

The present study demonstrated the efficacy of a paramylon moist dressing on wound healing using an animal model. The action of paramylon was also examined by measuring cytokine levels in mice serum by enzyme-linked immunosorbent assay.

\section{Materials and Methods}

All experiments were carried out in accordance with the Guide for the Care and Use of Laboratory Animals of the National Institute of Health and Use Committee of Osaka Prefecture University.

Preparation of paramylon film. Paramylon was obtained from euglena Co., Ltd. (Tokyo, Japan). Paramylon was dissolved in 1butyl-3-methylimidazolium chloride (BMImCI) and $\mathrm{N}, \mathrm{N}$ dimethylacetamide (DMAc). The optimum conditions to elicit a reaction is a temperature of $60-70^{\circ} \mathrm{C}$ and solvent mixture BMImCI /DMAc with a volume ratio of 5:2. The paramylon/BMImCI/DMAc liquid solution was coated on a glass layer by means of a bar coating method at $50-60^{\circ} \mathrm{C}$ to form a $700-\mu \mathrm{m}$ thin film. After the thin film was washed three times with methanol to remove the BMImCI/DMAc solvent, it was detached from the glass layer. The thin film was dried at room temperature for $2-3 \mathrm{~h}$ to achieve the final paramylon film $(20 \mu \mathrm{m})$.

Implants in mice. Male 8-week-old Jcl:ICR mice were used in this study. Animals were given food (CE-2, CLEA Japan, Inc., Tokyo, Japan) and water ad libitum, and were maintained on a light and dark cycle of $12 \mathrm{~h}$ each. Under chloral hydrate anesthesia $(400 \mathrm{mg} / \mathrm{kg}$, Wako Pure Chemical Industries, Osaka, Japan), the dorsal pilus was removed with a hair clipper and a gel mousse (Reckitt Benckiser, Tokyo, Japan). An epithelium was clipped out by using a biopsy punch $(8 \mathrm{~mm})$. Paramylon film $(8 \mathrm{~mm})$ or cellulose film $(8 \mathrm{~mm})$ was clamped on the wound with a dressing film (Johnson \& Johnson, NJ, USA). The control group was treated with the dressing film on the wound without Paramylon and cellulose film.

Biochemical determination. The extent of wound healing is expressed as the percentage of area remaining exposed as follows. Ratio of area $(\%)=[\mathrm{B}(1,3,5) / \mathrm{A}(0)] \times 100$, where $\mathrm{A}(0)$ and $\mathrm{B}(1,3,5)$ represent the exposed wound area at postoperative days 0 and 1,3 , and 5 , respectively (major $\times$ minor axes of the wound). Area of wound-healing dermis $\left(\mathrm{mm}^{2}\right)=\mathrm{C}(1,3,5)-\mathrm{B}(1,3,5)$, where $\mathrm{C}(1,3,5)$ and $\mathrm{B}(1,3,5)$ represent the area of wound-healing dermis (major $\times$ minor axes of wound) and the area of wound at postoperative days 1,3 , and 5 , respectively.

To measure cytokine levels in serum, blood samples were obtained from inferior vena cava in mice under anesthesia $(0.25 \%$ isoflurane) at days 3 and 5, respectively. Serum cytokines (IFN- $\gamma$, IL-6, IL-1 $\beta$, VEGF) were measured by the ELISA Development Kit according to manufacturer protocols (Peprotech, NJ, USA).

Statistical analysis. Data were analyzed with $\mathrm{R}$ (version $3 \cdot 4 \cdot 1$; The R Foundation, Vienna, Austria), EZR (version 1.3.6; Saitama Medical Center, Jichi Medical University, Shimotsuke, Japan), and 4 Steps Excel Tokei (OMS publishing Inc, Saitama, Japan). Results are expressed as mean \pm SE. The mean differences between groups were analyzed using one-way, two-way, and mixed between-withinsubjects analysis of variance (ANOVA), followed by Tukey-Kramer post-hoc tests. Normality was verified using the KolmogorovSmirnov test, and equality of variances was tested using Levene's test. A $p$-value $<0.05$ was considered statistically significant.

\section{Results}

Increased wound contraction in mice treated with paramylon film dressing. Figure 1 shows photographs of the wound region taken on days $0,1,3$, and 5. Gross observations revealed increased wound contraction in mice treated with paramylon film, compared with those treated with conventional cellulose film (Figure 1). Significant differences were detected in wound size on day 5. Significant changes were also found in dermis formation around the wounds treated with paramylon film (Figure 2). The area of wound healing dermis, an indicator of proliferation, approached the peak at day 5 in mice skin treated with paramylon, while the controls showed no such increase. There was no significant difference observed in body weight between groups after wounding (Figure 3 ).

Assessment of inflammatory cytokines in the mice undergoing treatment. To examine the action of paramylon, the effect of paramylon film dressing application on inflammatory cytokines in the serum of mice was investigated by ELISA. The groups treated with paramylon film showed significantly increased interferon gamma (IFN$\gamma$ ) levels at day 3 compared with the control group (Figure 4A). In contrast, the convention cellulose group showed a sustained increase in IFN- $\gamma$ levels at days 3 and 5. The levels of interleukin-6 (IL-6) in the serum were not statistically different among groups, although the convention cellulose group showed an increase at day 5 (Figure 4B).

The levels of vascular endothelial growth factor (VEGF), which is a key mediator of angiogenesis, were also tested (Figure 4C). The levels of VEGF in the groups treated with paramylon film were comparable to those in the control group, while the convention cellulose group showed a sustained increase in VEGF levels at days 3 and 5. 


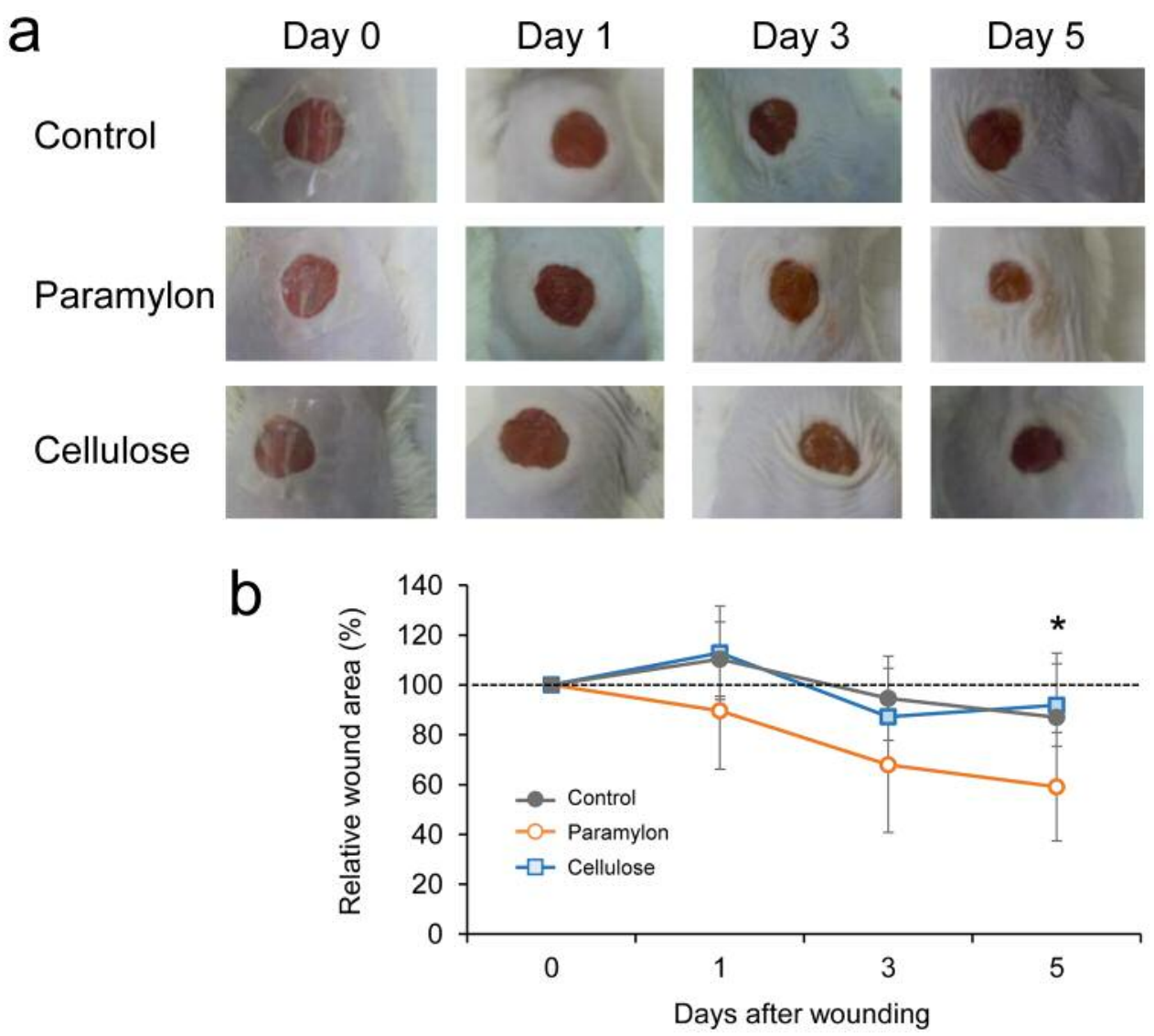

Figure 1. Effect of paramylon film dressing on wound healing in mice over time. A: Representative wound images of each group are shown up to day 5. B: The relative wound area (\%) revealed increased wound contraction induced by paramylon film dressing (mixed between-within-subjects ANOVA, Tukey-Kramer post-hoc test, $p<0.07$, paramylon vs. control at Day $5 ;{ }^{*} p<0.05$, paramylon vs. cellulose at Day 5). Bars are expressed as mean \pm SE ( $n=7)$.
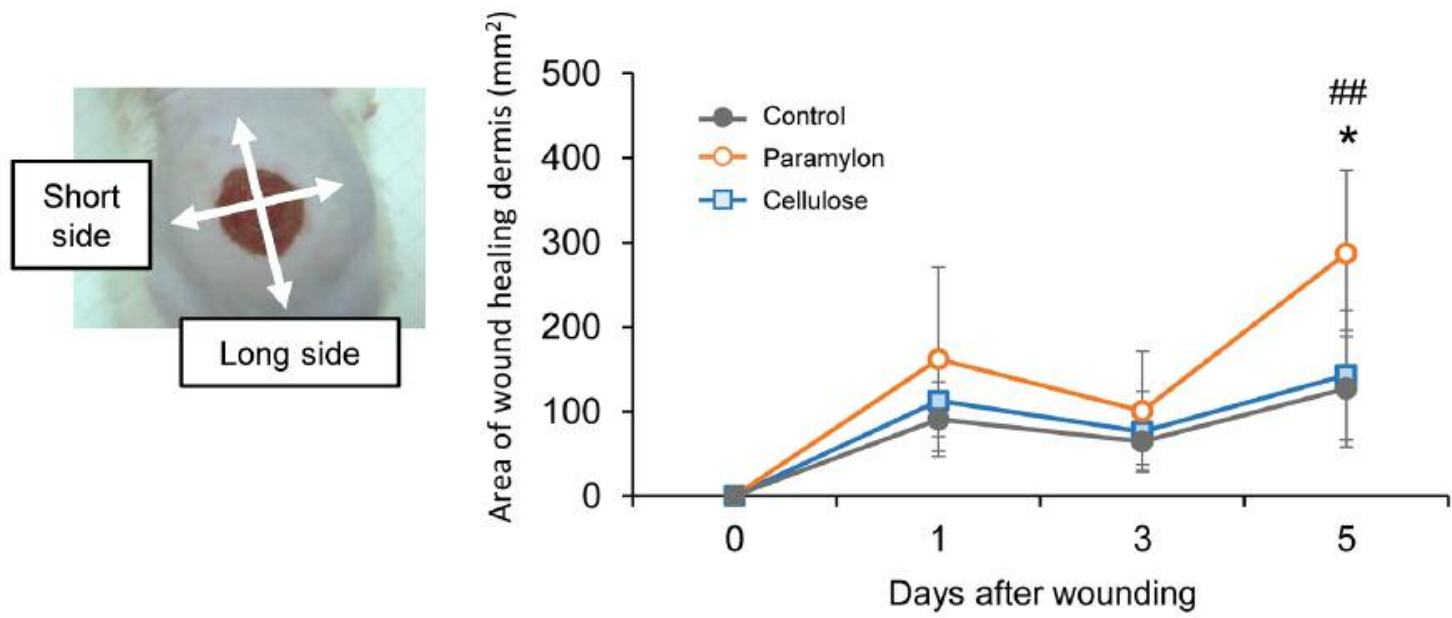

Figure 2. Effect of paramylon film dressing on wound healing in mice over time. The area of wound-healing dermis $\left(\mathrm{mm}^{2}\right)$ revealed changes in dermis formation around the wounds covered with paramylon film (mixed between-within-subjects ANOVA, Tukey-Kramer post-hoc test, \#\# $<<0.01$ paramylon vs. control at Day 5; * $<<0.05$ paramylon vs. cellulose at Day 5). Bars are expressed as mean $\pm S E(n=7)$. 
Inflammatory cytokines were reduced at day 3 and 5 in the empty dressing group (controls) (Figure 5), as shown in a previous study (29).

\section{Discussion}

In our study, $\beta$-glucan paramylon film application to an acute wound resulted in rapid wound contraction in mice. Our preliminary results indicate that the paramylon film dressing suppressed levels of inflammatory cytokines.

Paramylon treatment accelerated wound healing more rapidly than the cellulose treatment, accompanied with a modest increase of inflammatory cytokines. The moist and hydrophilic nature of $\beta$-glucan paramylon film provides an appropriate environment for healing. Similarly, bacterial cellulose maintains a moistenvironment at the wound surface and has a better ability to enhance the healing process of chronic wounds and burns compared to traditional dressings (30). Hydrocellular foam dressing promotes wound healing and upregulates synthesis of hyaluronan, which plays important roles in formation of scaffolds to promote tissue repair or regeneration, and biological functions such as cellular proliferation and migration at the time of wounding (31).

The immunomodulatory properties of $\beta$-glucans have been known for decades, which include macrophage and dendritic cell activation by binding with a primary receptor, Dectin-1, on their surfaces $(10,32)$. Macrophages are normally beneficial to the healing of wounds, although dysfunctional macrophage efferocytosis results in increased apoptotic cell burden at the wound site. This burden prolongs the inflammatory phase and complicates wound healing (33). Euglena $\beta$-glucan paramylon also upregulates inflammatory factors in lymphomonocytes. Moreover, the response of Euglena $\beta$-glucan-activated lymphomonocytes is much greater than that induced by commercially used $\beta$ glucans (34). Thus, paramylon film dressing applied to the skin might target and modulate macrophage function and seems to be a promising approach to promote wound healing.

Previously, $\beta$-glucan was shown to significantly stimulate phagocytic activity as well as potentiate the synthesis and release of inflammatory cytokines such as IL-1, IL-6 and TNF- $\alpha$ (35). $\beta$-Glucan increases the natural killer (NK) cellmediated destruction of cells, which also plays an important role in wound healing. One study showed that the activation of $\mathrm{NK}$ cells induced IFN- $\gamma$ production, which resulted in accelerated wound healing in mice (29). Stimulation of IFN$\gamma$ and TNF- $\alpha$ facilitates chronic wound healing in diabetic rats and normalizes the defect in VEGF regulation associated with diabetes-induced skin-repair disorders (36). An accelerated wound healing process in the early phase may account for rapid wound contraction observed following the application of paramylon film.

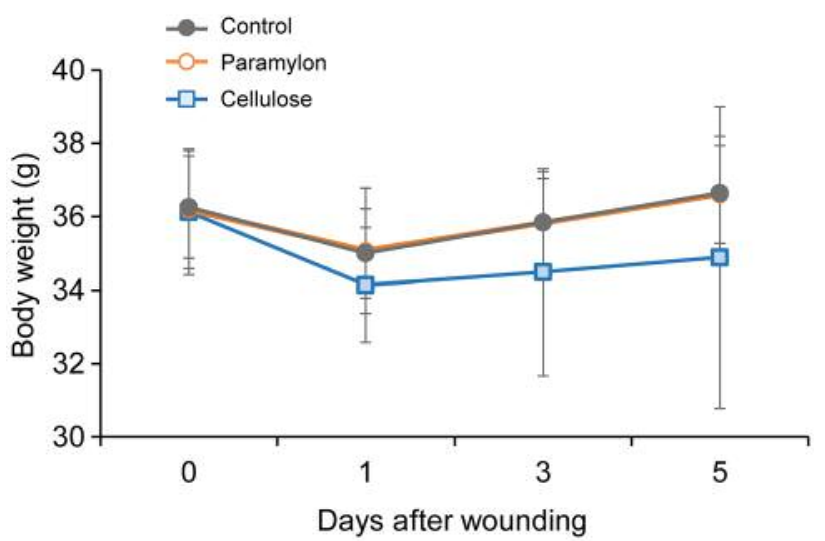

Figure 3. Changes in mouse body weight after wounding. There was no difference between groups in mouse body weight after wounding (mixed between-within-subjects ANOVA, main effect of group $p=0.396)$. Bars are expressed as mean $\pm S E(n=7)$.

In a previous study, oral administration of paramylon significantly reduces the secretion of the cytokines IL-17, IL-6, and IFN- $\gamma$ in lymphoid tissues, resulting in suppression of the onset of arthritis in rodent models (37). Paramylon improved the symptoms of atopic dermatitis and decreased the secretion of IL- 4 , IFN- $\gamma$, IL-18, and IL-12 in NC/Nga mice (23). Similarly, administration of $\beta$-1,3/1,6-glucans from yeast cell wall showed a tendency to reduce production of IFN- $\gamma$ in a murine tumor model (38). Based on these results, it is postulated that paramylon regulates excessive immune responses, resulting in accelerated wound healing on the skin when using it as a film dressing. Successful resolution of inflammation minimizes excessive tissue injury, suppresses chronic inflammation, and prevents the development of chronic diseases (39). IFN- $\gamma$ expression in wounded tissues reached peak levels at $12 \mathrm{~h}$ in mice, which was significantly decreased three days after wounding (29). However, inflammation of long duration delays the healing process. An excessive increase of VEGF expression in granulation tissue impairs angiogenesis in wound healing in diabetes (40). In contrast, the inflammatory cytokine response is reduced in fetal tissues, which may be responsible for the lack of cellular recruitment and inflammation seen in fetal wound healing and may contribute to scar-less fetal wound healing (41). Here, the reduction of inflammatory cytokines after wounding suggests that paramylon may have anti-inflammatory capabilities in wound healing.

In conclusion, $\beta$-glucan paramylon film accelerated wound healing of the skin in an animal model, accompanied with a modest increase of inflammatory cytokines. Due to its ability to down-regulate inflammations, paramylon is very promising as an alternative immunosuppressive material to treat inflammatory diseases, as physiological functions of 

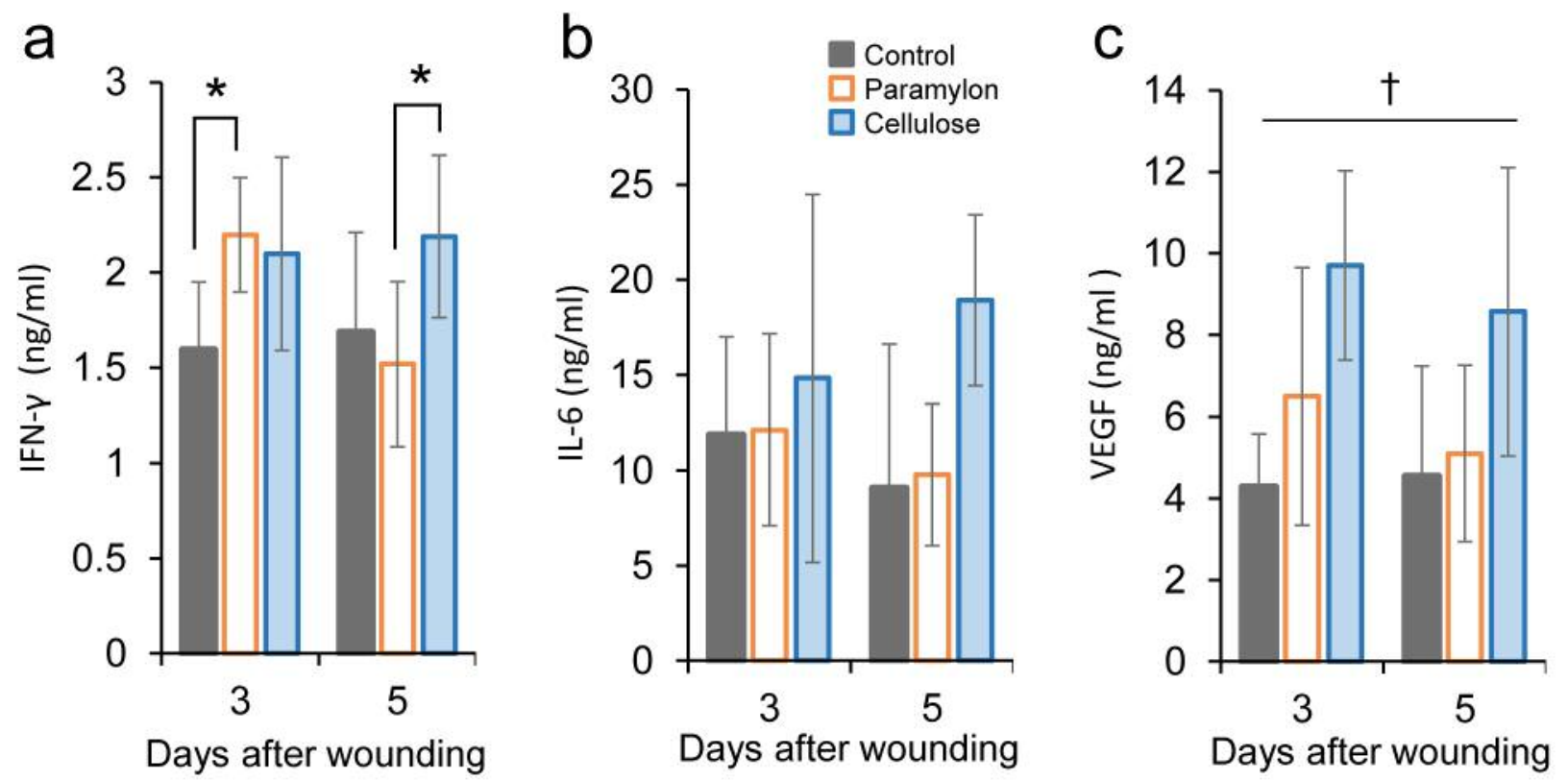

Figure 4. Effect of paramylon film dressing on inflammatory cytokines in mouse serum. Serum cytokines were measured by ELISA. A: IFN- $\gamma$ level was increased on day 3 in mice with paramylon film dressing, that was decreased on day 5, but sustained on day 5 in mice with cellulose film dressing (two-way ANOVA, Tukey-Kramer post-hoc test, *p<0.05) B: Change of IL-6 on days 3 and 5 after wounding in each group (two-way ANOVA, Tukey-Kramer post-hoc test, n.s.). C: VEGF level was increased at days 3 and 5 in mice with cellulose film dressing (two-way ANOVA, Tukey-Kramer post-hoc test, ${ }^{\dagger} p<0.05$ cellulose vs. control and paramylon). Bars are expressed as mean $\pm S E$ (control: $n=6$ and 5; paramylon: $n=6$ and 6; cellulose: $n=7$ and 7 on days 3 and 5).

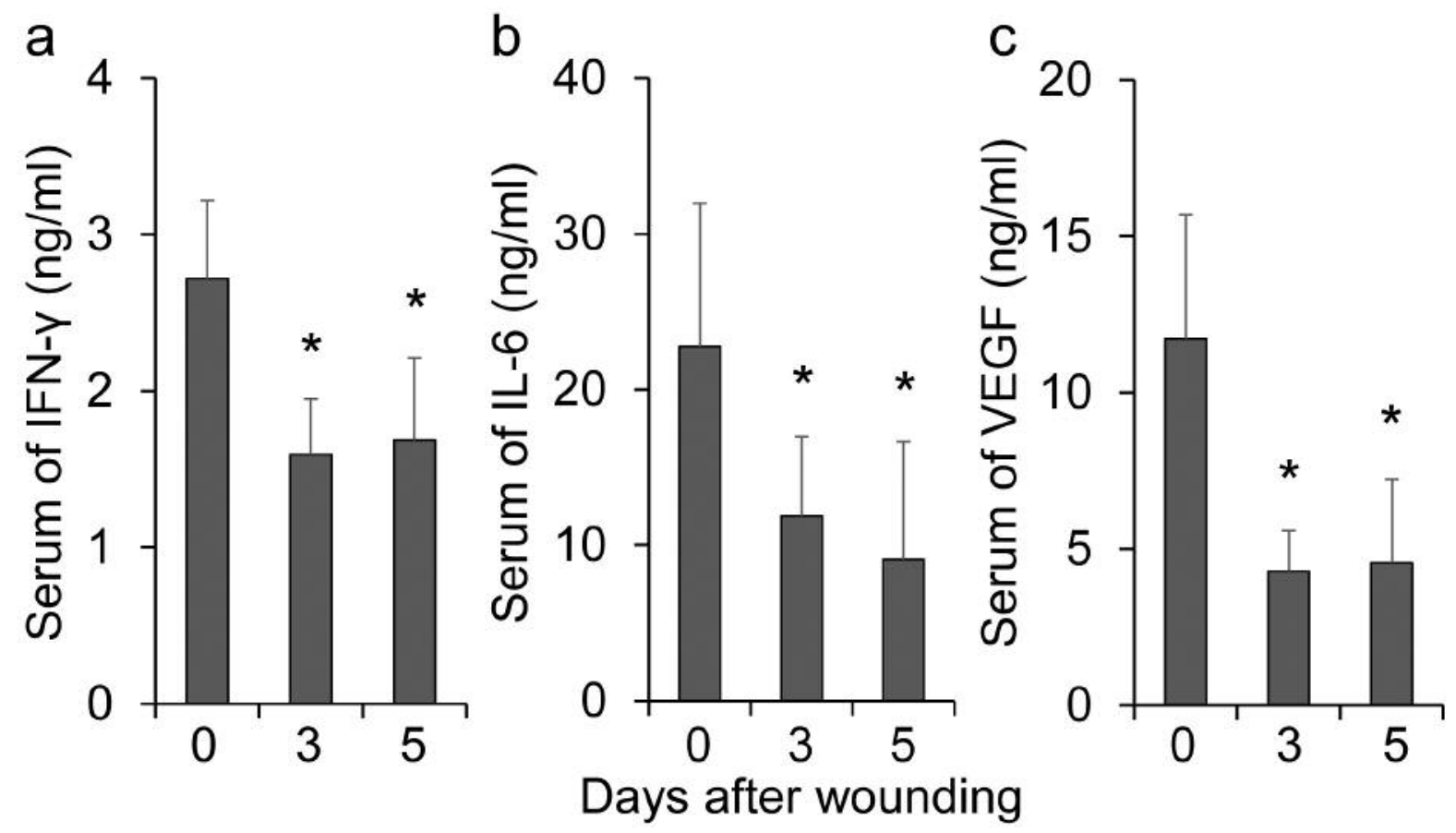

Figure 5. Changes in inflammatory cytokines after wounding in the serum of mice. Serum cytokines were measured by ELISA in mice with conventional wound dressing (controls). A: Changes in IFN- $\gamma$ in the serum of mice (one-way ANOVA, Tukey-Kramer post-hoc test, *p<0.01 vs. Day 0). B: Changes in IL-6 in the serum of mice (one-way ANOVA, Tukey-Kramer post-hoc test, *p<0.01 vs. Day 0) C: Changes in VEGF in the serum of mice (one-way ANOVA, $p<0.01$; Tukey-Kramer post-hoc test, $p<0.01$ vs. Day 0). Bars are expressed as mean $\pm S E$ ( $n=7,6$, and 6 at days 0,3 , and 5 , respectively). 
$\beta$-glucan depend on their structure, such as size of the molecule, composition of the glucan backbone, types and frequency of side chain $(9,42)$. To the best of our knowledge, the present study is the first application of $\beta$-glucan paramylon directly affecting the course of wound healing. The successful acceleration of wound healing in mice suggests the potential use of paramylon film in humans for wound care.

\section{Conflicts of Interest}

Kosuke Yasuda, Ayaka Nakashima, and Kengo Suzuki are employees of euglena Co., Ltd.

\section{Acknowledgements}

The Authors thank Mr. Hideki Yamaguchi and Ms. Ayako Maruta, KRI Inc. (www.kri-inc.jp), for preparation of a paramylon film. The Authors also thank Editage (www.editage.jp) for English language editing. All the experiments were carried out in accordance with the Guide for the Care and Use of Laboratory Animals of the National Institute of Health.

\section{References}

1 Gwak JH and Sohn SY: Identifying the trends in wound-healing patents for successful investment strategies. PLoS One 12(3): 119, 2017.

2 Dhivya S, Padma VV and Santhini E: Wound dressings - a review. BioMedicine 5(4): 22, 2015.

3 Moraes PRF de S, Saska S, Barud H, Lima LR de, Martins V da CA, Plepis AM de G, Ribeiro SJL, Gaspar AMM, Moraes PRF de S, Saska S, Barud H, Lima LR de, Martins V da CA, Plepis AM de G, Ribeiro SJL and Gaspar AMM: Bacterial cellulose/collagen hydrogel for wound healing. Mater Res 19(1): 106-116, 2016.

4 Khalid A, Ullah H, Ul-Islam M, Khan R, Khan S, Ahmad F, Khan T and Wahid F: Bacterial cellulose-TiO 2 nanocomposites promote healing and tissue regeneration in burn mice model. RSC Adv 7(75): 47662-47668, 2017.

5 Sun BK, Siprashvili Z and Khavari PA: Advances in skin grafting and treatment of cutaneous wounds. Science 346(6212): 941-945, 2014.

6 Kondo T: Timing of skin wounds. Leg Med (Tokyo) 9(2): 109114, 2007

7 Boateng JS, Matthews KH, Stevens HNE and Eccleston GM: Wound Healing Dressings and Drug Delivery Systems: A Review. J Pharm Sci 97(8): 2892-923, 2008.

8 Demidova-Rice TN, Hamblin MR and Herman IM: Acute and impaired wound healing: pathophysiology and current methods for drug delivery, part 1: normal and chronic wounds: biology, causes, and approaches to care. Adv Skin Wound Care 25(7): 304-314, 2012.

9 Nakashima A, Yamada K, Iwata O, Sugimoto R, Atsuji K, Ogawa T, Ishibashi-Ohgo N, and Suzuki K: $\beta$-Glucan in foods and its physiological functions. J Nutr Sci Vitaminol (Tokyo) 64(1): 8-17, 2018.

10 Vannucci L, Sima P, Vetvicka V, Krizan J, Vannucci L, Sima P, Vetvicka V and Krizan J: Lentinan Properties in Anticancer Therapy: A Review on the Last 12-Year Literature. Am J Immunol 13(1): 50-61, 2017.
11 Oba K, Kobayashi M, Matsui T, Kodera Y and Sakamoto J: Individual patient based meta-analysis of lentinan for unresectable/recurrent gastric cancer. Anticancer Res 29(7): 2739-2745, 2009.

12 Yin X, Ying J, Li L, Zhang $\mathrm{H}$ and Wang $\mathrm{H}$ : A meta-analysis of lentinan injection combined with chemotherapy in the treatment of nonsmall cell lung cancer. Indian J Cancer 52(5): 29-31, 2015.

13 Brown GD and Gordon S: Fungal beta-glucans and mammalian immunity. Immunity 19(3): 311-315, 2003.

14 Ross GD, Větvička V, Yan J, Xia Y and Větvičková J: Therapeutic intervention with complement and $\beta$-glucan in cancer. Immunopharmacology 42(1-3): 61-74, 1999.

15 Cleary JA, Kelly GE and Husband AJ: The effect of molecular weight and beta-1,6-linkages on priming of macrophage function in mice by $(1,3)$-beta-D-glucan. Immunol Cell Biol 77(5): 395403, 1999.

16 Soltys J and Quinn MT: Modulation of endotoxin- and enterotoxin-induced cytokine release by in vivo treatment with beta-(1,6)-branched beta-(1,3)-glucan. Infect Immun 67(1): 244252, 1999.

17 Hashimoto T, Ohno N, Adachi Y and Yadomae T: Enhanced production of inducible nitric oxide synthase by $\beta$-glucans in mice. FEMS Immunol Med Microbiol 19(2): 131-135, 2006.

18 Kernodle DS, Gates H and Kaiser AB: Prophylactic antiinfective activity of poly-[1-6]-beta-D-glucopyranosyl-[1-3]beta-D-glucopryanose glucan in a guinea pig model of staphylococcal wound infection. Antimicrob Agents Chemother 42(3): 545-549, 1998.

19 Wei D, Williams D and Browder W: Activation of AP-1 and SP1 correlates with wound growth factor gene expression in glucantreated human fibroblasts. Int Immunopharmacol 2(8): 1163$1172,2002$.

20 Zykova SN, Balandina KA, Vorokhobina NV, Kuznetsova AV, Engstad R and Zykova TA: Macrophage stimulating agent soluble yeast $\beta-1,3 / 1,6$-glucan as a topical treatment of diabetic foot and leg ulcers: A randomized, double blind, placebo-controlled phase II study. J Diabetes Investig 5(4): 392-399, 2014.

21 Berdal M, Appelbom HI, Eikrem JH, Lund A, Busund L-T, Hanes R, Seljelid R and Jenssen T: Aminated $\beta-1,3-\mathrm{D}$-glucan has a dose-dependent effect on wound healing in diabetic $\mathrm{db} / \mathrm{db}$ mice. Wound Repair Regen 19(5): 579-587, 2011.

22 Nakashima A, Suzuki K, Asayama Y, Konno M, Saito K, Yamazaki $\mathrm{N}$ and Takimoto $\mathrm{H}$ : Oral administration of Euglena gracilis $\mathrm{Z}$ and its carbohydrate storage substance provides survival protection against influenza virus infection in mice. Biochem Biophys Res Commun 494(1-2): 379-383, 2017.

23 Sugiyama A, Hata S, Suzuki K, Yoshida E, Nakano R, Mitra S, Arashida R, Asayama Y, Yabuta Y and Takeuchi T: Oral administration of paramylon, a beta-1,3-D-glucan isolated from Euglena gracilis $\mathrm{Z}$ inhibits development of atopic dermatitis-like skin lesions in NC/Nga mice. J Vet Med Sci 72(6): 755-763, 2010.

24 Sugiyama A, Suzuki K, Mitra S, Arashida R, Yoshida E, Nakano $\mathrm{R}$, Yabuta $\mathrm{Y}$ and Takeuchi T: Hepatoprotective effects of paramylon, a beta-1, 3-D-glucan isolated from Euglena gracilis $\mathrm{Z}$, on acute liver injury induced by carbon tetrachloride in rats. J Vet Med Sci Japanese Soc Vet Sci 71(7): 885-890, 2009.

25 Sakagami H, Kikuchi K, Takeda M, Sato T, Ichikawa S, Fujimaki M, Wada C and Komatsu N: Macrophage stimulation activity of antimicrobial $\mathrm{N}, \mathrm{N}$-dimethylaminoethyl paramylon. In Vivo 5(2): 101-105, 1991. 
26 Shibakami M, Tsubouchi G, Nakamura M and Hayashi M: Preparation of carboxylic acid-bearing polysaccharide nanofiber made from euglenoid $\beta$-1,3-glucans. Carbohydr Polym 98(1): 95-101, 2013

27 Shibakami M, Tsubouchi G, Sohma M and Hayashi M: One-pot synthesis of thermoplastic mixed paramylon esters using trifluoroacetic anhydride. Carbohydr Polym 119: 1-7, 2015.

28 Shibakami M, Tsubouchi G, Sohma M and Hayashi M: Preparation of transparent self-standing thin films made from acetylated euglenoid $\beta$-1,3-glucans. Carbohydr Polym 133: 421 428, 2015.

29 Tanno H, Kawakami K, Ritsu M, Kanno E, Suzuki A, Kamimatsuno R, Takagi N, Miyasaka T, Ishii K, Imai Y, Maruyama $\mathrm{R}$ and Tachi M: Contribution of invariant natural killer T Cells to skin wound healing. Am J Pathol 185(12): 32483257, 2015.

30 Czaja WK, Young DJ, Kawecki M and Brown RM Jr.: The Future Prospects of Microbial Cellulose in Biomedical Applications. Biomacromolecules 8(1): 1-12, 2006.

31 Yamane T, Nakagami G, Yoshino S, Muramatsu A, Matsui S, Oishi Y, Kanazawa T, Minematsu $\mathrm{T}$ and Sanada $\mathrm{H}$ : Hydrocellular Foam Dressing Promotes Wound Healing along with Increases in Hyaluronan Synthase 3 and PPAR $\alpha$ Gene Expression in Epidermis. PLoS One 8(8): 1-6, 2013.

32 Brown GD and Gordon S: Immune recognition: A new receptor for $\beta$-glucans. Nature 413(6851): 36-37, 2001.

33 Koh TJ and DiPietro LA: Inflammation and wound healing: the role of the macrophage. Expert Rev Mol Med 13: 23, 2011.

34 Russo R, Barsanti L, Evangelista V, Frassanito AM, Longo V, Pucci L, Penno G and Gualtieri P: Euglena gracilis paramylon activates human lymphocytes by upregulating pro-inflammatory factors. Food Sci Nutr 5(2): 205-214, 2017.

35 Vetvicka V and Yvin JC: Effects of marine $\beta-1,3$ glucan on immune reactions. Int Immunopharmacol 4(6): 721-730, 2004.
$36 \mathrm{Gu} \mathrm{X}$, Shen S, Huang C, Liu Y, Chen Y, Luo L, Zeng Y and Wang A: Effect of activated autologous monocytes/macrophages on wound healing in a rodent model of experimental diabetes. Diabetes Res Clin Pract 102(1): 53-59, 2013.

37 Suzuki K, Nakashima A, Igarashi M, Saito K, Konno M, Yamazaki $\mathrm{N}$ and Takimoto $\mathrm{H}$ : Euglena gracilis $\mathrm{Z}$ and its carbohydrate storage substance relieve arthritis symptoms by modulating Th17 immunity. PLoS One 13(2): e0191462, 2018.

38 Harnack U, Eckert K and Pecher G: Role of soluble $\beta$-(1-3),(16)-D-glucan from Saccharomyces cerevisiae in the murine P388 ascites tumor model. In Vivo 25(2): 185-189, 2011.

39 Gilroy DW, Lawrence T, Perretti M and Rossi AG: Inflammatory Resolution: new opportunities for drug discovery. Nat Rev Drug Discov 3(5): 401-416, 2004.

40 Katagiri S, Park K, Maeda Y, Rao TN, Khamaisi M, Li Q, Yokomizo H, Mima A, Lancerotto L, Wagers A, Orgill DP and King GL: Overexpressing IRS1 in endothelial cells enhances angioblast differentiation and wound healing in diabetes and insulin resistance. Diabetes 65(9): 2760-2771, 2016.

41 Liechty KW, Crombleholme TM, Cass DL, Martin B and Adzick NS: Diminished interleukin-8 (IL-8) production in the fetal wound healing response. J Surg Res 77(1): 80-84, 1998.

42 Javmen A, Nemeikaitè-Čènienè A, Bratchikov M, Grigiškis S, Grigas F, Jonauskienė I, Zabulyte D and Mauricas M: $\beta$-Glucan from Saccharomyces cerevisiae Induces IFN- $\gamma$ Production In Vivo in BALB/c Mice. In Vivo 29(3): 359-363, 2015.

Received April 4, 2018

Revised May 8, 2018

Accepted May 9, 2018 